\title{
A Comparison Study of Indoor and Outdoor Air Quality in Nanjing, China
}

\author{
Ruochong Xu' ${ }^{1,2}$, Ximeng Qi ${ }^{1,2 *}$, Guoqing Dai ${ }^{1,2}$, Haoxian Lin ${ }^{1,2}$, Jiachun Shi ${ }^{1,2}$, Chengxu Tong ${ }^{1,2}$, \\ Peng Zhai ${ }^{1,2}$, Caijun Zhu ${ }^{1,2}$, Lei Wang ${ }^{1,2}$, Aijun Ding ${ }^{1,2}$
}

${ }^{1}$ Joint International Research Laboratory of Atmospheric and Earth System Sciences, School of Atmospheric Sciences, Nanjing University, Nanjing 210023, China

${ }^{2}$ Jiangsu Provincial Collaborative Innovation Center for Climate Change, Nanjing 210023, China

\begin{abstract}
Because humans spend much of their time in indoor microenvironments, the air quality indoors has attracted significant attention. This study simultaneously conducted real-time indoor observations and comprehensive outdoor measurements of $\mathrm{O}_{3}, \mathrm{CO}$ and $\mathrm{PM}_{2.5}$ in suburban Nanjing in eastern China from September to December 2018. The $\mathrm{O}_{3}, \mathrm{CO}_{\text {and }} \mathrm{PM}_{2.5}$ exhibited median indoor concentrations of $3.2 \mathrm{ppb}, 395.8 \mathrm{ppb}$ and $17.3 \mu \mathrm{g} \mathrm{m}^{-3}$, respectively, based on measurements in a room with closed windows and relatively regular daily indoor human activity, and median outdoor values of $30.5 \mathrm{ppb}, 386.1 \mathrm{ppb}$ and $37.2 \mu \mathrm{g} \mathrm{m}^{-3}$, resulting in median indoor-outdoor $(\mathrm{I} / \mathrm{O})$ ratios of $0.14,1.01$ and 0.46 . Moreover, the indoor concentrations traced the outdoor variations with correlations of approximately $0.68,0.82$ and 0.82 for the $\mathrm{O}_{3}, \mathrm{CO}$ and $\mathrm{PM}_{2.5}$, respectively. During pollution episodes, the indoor $\mathrm{O}_{3}$ and $\mathrm{PM}_{2.5}$ concentrations reached about $30 \mathrm{ppb}$ and $130 \mu \mathrm{g} \mathrm{m}{ }^{-3}$, respectively. Both meteorological conditions (e.g., wind speed or relative humidity) and human activity indoors influenced the relationships between the indoor and outdoor concentrations, including the I/O ratios and time lag. A simplified indoor-outdoor massbalance equation was developed to simulate the indoor concentrations, and the predictions fitted the observed data for most of the testing period, especially after considering the human activity indoors and limited penetration of particles. This study enhances our understanding of the indoor-outdoor relationships for gaseous and particulate matter concentrations in polluted areas such as the Yangtze River Delta and highlights the urgent need for improving indoor air quality in the megacities of China.
\end{abstract}

Keywords: Air quality; Indoor measurements; I/O ratio; Yangtze River Delta.

\section{INTRODUCTION}

Indoor air quality has been debated and investigated widely in recent years because of the potential detrimental impact of air pollutants on human health (Passarelli, 2009; Choo and Jalaludin, 2015; Wolkoff, 2018). Numerous epidemiological studies have reported that air pollutants were associated with short- and long-term negative impact on health, including higher morbidity of cardiovascular and respiratory diseases (Donaldson et al., 2002; Pope III et al., 2002; Pope III and Dockery, 2006; Sousa et al., 2013), increased mortality (Samet et al., 2000; Bell et al., 2005; Chen et al., 2012), and even adverse birth outcomes (Astrup, 1972; Nieuwenhuijsen et al., 2013). As people spend more time in indoor microenvironments (Spalt et al., 2016), indoor air quality must be concerned owing to its potential risks to human health.

\footnotetext{
* Corresponding author.

E-mail address: qiximeng@nju.edu.cn
}

Research on indoor air quality has been conducted in a variety of indoor microenvironments in different countries and regions (Chen and Zhao, 2011; Fadeyi, 2015; Liu and Zhang, 2019). Factors that have significant influences on indoor concentrations have been elucidated, among which outdoor concentration is a predominant factor dominating indoor concentration for most investigated gases and particles (Weschler and Shields, 1997; Abt et al., 2000; Loupa et al., 2006; Walker and Sherman, 2013; Zhong et al., 2013). Other factors include indoor sources and deposits, the building infiltration, natural and mechanical ventilation and recirculation of air etc. (Hayes, 1991; Lunden et al., 2003; Chen and Zhao, 2011; Cros et al., 2012). Presence of indoor sources, such as re-suspension of particles due to walking, emission from smoking and other domestic or office equipment, can impose remarkable effects on the concentrations of indoor air pollutants (Stranger et al., 2007; Fazlzadeh et al., 2015). Surfaces of indoor materials can remove some gases like ozone (Lamble et al., 2011; Gall et al., 2013) and are meanwhile where particulate matter deposits (Liu et al., 2014). Moreover, ventilation rate significantly affects the indoor-outdoor relationships when 
the ventilation system is on (Koponen et al., 2001). Besides factors associated with building structure and indoor layout, outdoor meteorological parameters, such as wind speed, wind direction, temperature and relative humidity, also play critical parts (Riain et al., 2003; Elbayoumi et al., 2013; Chithra and Nagendra, 2014; Zhao et al., 2015). In particular, based on the studies of the influential factors on indoor-outdoor relationships, mass-balance models were established in some research to predict the indoor concentrations of pollutants (Hayes, 1989; Du et al., 2018; Tang et al., 2018).

In China, rapid urbanization and industrialization have brought about serious issues of air pollution (Chan and Yao, 2008; Liu et al., 2015). However, currently the majority of research mainly focuses on outdoor air pollution. Some indoor measurements have been conducted in some cities of China, e.g., Guangzhou, Dalian and Chengdu, focusing on pollutants like $\mathrm{PM}_{2.5}$ and formaldehyde (Zhao et al., 2004; Huang et al., 2007; Liu et al., 2018). In Yangtze River Delta of China, some indoor measurements on $\mathrm{PM}_{2.5}$ and gases have been carried out, e.g., in Nanjing, Shanghai and Hangzhou (Weng et al., 2010; Zhong et al., 2013; Hu et al., 2015; Wang et al., 2016; Shao et al., 2017; Bi et al., 2018). Zhong et al. (2013) investigated the indoor and outdoor CO concentrations in Shanghai and found they were comparable and had good correlation in a single-side natural ventilating room without internal source. Shao et al. (2017) and Bi et al. (2018) measured indoor and outdoor concentrations of fine particulate matter in Yangtze River Delta and found the averaged indoor $\mathrm{PM}_{2.5}$ concentration was higher than the indoor air quality guideline published by the World Health Organization. Additionally, the relationships between indoor and outdoor $\mathrm{PM}_{2.5}$ concentrations were found to be different depending on the various indoor microenvironments (Bi et al., 2018). Hu et al. (2015) found that indoor acidic and oxidizing gaseous pollutants, i.e., $\mathrm{SO}_{2}, \mathrm{NO}_{2}$ and $\mathrm{O}_{3}$, had potential physical and chemical damage to objects indoors. However, many of them collected data merely for short periods (e.g., $<1$ month) with relatively coarse time resolution. Compared with the increasing outdoor air pollution measurements, continuous indoor air quality measurements with high time resolution are still significantly fewer. Moreover, the discussions on the relationships between indoor air quality and meteorological conditions are lacking.

To better understand the indoor air quality in the western Yangtze River Delta of China, the measurement was carried out in the room of suburban Nanjing, with relatively good air-tightness, unobvious indoor sources of gases measured, and fairly regular human activities indoors. Continuous monitoring on indoor/outdoor $\mathrm{O}_{3}, \quad \mathrm{CO}$ and $\mathrm{PM}_{2.5}$ concentrations was conducted for about three months. In this study, we studied the features of indoor and outdoor concentrations of $\mathrm{O}_{3}, \mathrm{CO}$ and $\mathrm{PM}_{2.5}$ in detail. In particular, to better evaluate the impact of both human activities and meteorological factors, the $\mathrm{O}_{3}$ and $\mathrm{PM}_{2.5}$ pollution episodes were selected and analyzed. Finally, a prediction method was established based on the mass-balance equation. Those findings can provide meaningful references for further research on effects of atmospheric gases and particles on indoor microenvironments and help the development of methods for the control of indoor air pollutants.

\section{METHODS}

\section{The Sampling Site and Indoor Environment}

The measurement campaign was carried out at SORPES station (Station for Observing Regional Processes of the Earth System), the location of which is in the campus of Nanjing University $\left(118^{\circ} 57^{\prime} 10^{\prime \prime} \mathrm{E}, 32^{\circ} 07^{\prime} 14^{\prime \prime} \mathrm{N}\right)$, suburban part of Nanjing $20 \mathrm{~km}$ away from downtown area. The station is located on a $40 \mathrm{~m}$ high hill and no tall building surrounds it. The SORPES station is heavily instrumented to monitor the outdoor pollutants from both the North China Plain and Yangtze River Delta. The outdoor meteorological conditions, including temperature, relative humidity, wind speed and direction etc., are observed at SORPES as well. During the measurement, the outdoor temperature and relative humidity were $5.1-28.2^{\circ} \mathrm{C}$ and $18.6-98.6 \%$ (mean: $16.1^{\circ} \mathrm{C}$ and $68.3 \%$, respectively). Wind speed was $0.0-5.9 \mathrm{~m} \mathrm{~s}^{-1}$ and prevailing wind direction was northeast (mean: $1.4 \mathrm{~m} \mathrm{~s}^{-1}$ and $52.5^{\circ}$, respectively). Rainfall occurred occasionally with intensity from 0.1 to $4.8 \mathrm{~mm} \mathrm{~h}^{-1}$ during the measurements. More details about SORPES station are described in Ding et al. (2016). To study the indoor air quality, continuous real-time indoor monitoring of $\mathrm{O}_{3}$ and $\mathrm{CO}$ concentrations was conducted from September to November 2018. Moreover, considering the frequent PM pollution in late autumn and winter in Yangtze River Delta, intermittent but fairly regular real-time sampling of indoor $\mathrm{PM}_{2.5}$ mass concentration was conducted from October to December 2018.

The indoor measurements of $\mathrm{O}_{3}, \mathrm{CO}$ and $\mathrm{PM}_{2.5}$ were conducted in a room of SORPES station, which is mainly used as the space for the long-term placement of measurement instruments. As shown in Fig. 1, the features of the room, such as the building structure and ventilation, are similar with the residential buildings. The room has a floor area of $25 \mathrm{~m}^{2}$ with a small attic whose area is $12.5 \mathrm{~m}^{2}$. A $1 \mathrm{~m}^{2}$ skylight allows sunlight to enter the room through the window glass. All the windows were kept closed during the measurement period, and the door was not open for most of the time. An air conditioner without indoor-outdoor air exchange function was on constantly during the measurement period, which kept the indoor temperature relatively stable. The setting was inclined to get good air-tightness, which was equated to low indoor-outdoor exchange rate. Indoor human activities occurred routinely from 09:00 LT to 12:00 LT and from 15:00 LT to 18:00 LT every day including weekdays and weekends, although occasional exceptions may happen. During the everyday periods of occupancy, the room was generally occupied by 1-3 staff. Smoking was seriously prohibited in the room. There are no obvious $\mathrm{O}_{3}$ and $\mathrm{CO}$ sources inside the room and the re-suspension of particles due to walking and some other activities can be regarded as the only indoor source of $\mathrm{PM}_{2.5}$ in specific periods of time as mentioned above. The sample inlets of instruments for outdoor measurements were installed on the roof of SORPES station less than $10 \mathrm{~m}$ from the windows of the room where indoor measurement was conducted, and simultaneously, for 
(a)



(b)



Fig. 1. Indoor microenvironment of the sampling room in this study: (a) vertical view and (b) 3-D picture. Note: the positions of the instruments are shown in the figures (red: indoor observation instruments; blue: outdoor observation instruments).

indoor monitoring, the inlets of instruments were set indoors $1.0 \mathrm{~m}$ above the ground and $1.5 \mathrm{~m}$ away from the window of the western side in the room (Fig. 1).

\section{Instrumentation}

Indoor monitoring of $\mathrm{O}_{3}$ volume fraction concentrations was carried out using a photometric ozone analyzer (Model T400; Teledyne API) while outdoor measurement relied on a Thermo Scientific Model 49i. The measurement principles of two instruments were the same based on the Beer-Lambert law and the comparison between gas stream containing $\mathrm{O}_{3}$ and a stream that had been scrubbed of $\mathrm{O}_{3}$. The resolutions were both $0.1 \mathrm{ppb}$ and the counting intervals were both set to be 5 minutes during the sampling period. For $\mathrm{CO}$ volume fraction concentrations, indoor and outdoor monitoring was conducted by a CO analyzer with auto-reference (Model T300U; Teledyne API). The measurement principle was based on Beer-Lambert law and comparison between concentrations of $\mathrm{CO}$ and the other neutral gas. The $\mathrm{CO}$ concentrations were computed by taking the ratio of the instantaneous values of both gases and then compensating the ratio for sample temperature and pressure. The measurement range was from 0 to $100 \mathrm{ppm}$ with precision getting $0.5 \%$ reading. The counting interval was set as 5 minutes during the sampling period. The comparison between instruments for indoor and outdoor $\mathrm{O}_{3}$ and $\mathrm{CO}$ measurements was conducted by synchronously measuring outdoor samplings before the campaign. The correlations between indoor and outdoor $\mathrm{O}_{3}$ and $\mathrm{CO}$ instruments were both satisfying, with correlation coefficient $r=0.99$ and 0.98 , root mean square error $(\mathrm{RMSE})<3.0 \mathrm{ppb}$ and $<45 \mathrm{ppb}$, respectively.

Outdoor $\mathrm{PM}_{2.5}$ mass concentration was monitored by a SHARP 5030i (Thermo Scientific) based on light scattering of aerosols and the principle of $\beta$ attenuation. The sensitivity of the instrument was $0.1 \mu \mathrm{g} \mathrm{m}^{-3}$ with the range allowed from 0 to $10,000 \mu \mathrm{g} \mathrm{m}^{-3}$, and the counting interval was 5 minutes. For the indoor measurement of $\mathrm{PM}_{2.5}$ mass concentration, a SidePak Personal Aerosol Monitor AM510 (TSI Inc.) was used, which relied on $90^{\circ}$ light scattering and laser diode, whose minimum resolution was $1 \mu \mathrm{g} \mathrm{m}^{-3}$ and range was from 1 to $20,000 \mu \mathrm{g} \mathrm{m}^{-3}$. The counting interval was set to be 1 minute. Due to the different operation principles between the SHARP 5030 $i$ and SidePak AM510, it is necessary to convert the data acquired by the SidePak AM510 towards the standard of the SHARP 5030i, which has been viewed as the reference instrument with good stability and high accuracy. The comparison between the two instruments was carried out before the indoor-outdoor campaign. Linear fitting was used and shown satisfying result:

$\mathrm{PM}_{2.5}($ SHARP 5030i $)=0.43 \times \mathrm{PM}_{2.5}($ SidePak AM510 $)$; $\mathrm{r}=0.92, \mathrm{p}<0.001$

During the later indoor-outdoor measurement, indoor data gained by the SidePak AM510 was converted to the standard of the SHARP 5030i using the linear fitting equation above.

\section{RESULTS AND DISCUSSION}

\section{The Time Series and Statistical Results}

As presented in Table 1, for $\mathrm{O}_{3}$, the statistical results fluctuated between 0.9 and $26.6 \mathrm{ppb}$ indoors (average: $4.5 \mathrm{ppb}$; median: $3.2 \mathrm{ppb}$ ), and 0.0 and $105.7 \mathrm{ppb}$ outdoors (average: $32.5 \mathrm{ppb}$; median: $30.5 \mathrm{ppb}$ ). Except the minimum value, the statistical values of outdoor $\mathrm{O}_{3}$ concentrations mentioned above were all higher than those from indoor measurement. 
As shown in Fig. 2(a), the outdoor concentrations of $\mathrm{O}_{3}$ were much higher during most of the measurement period, especially in daytime. This resulted from the active photoreactions outdoors generating large amount of outdoor $\mathrm{O}_{3}$, while indoor concentrations relied predominantly on indoor-outdoor transport with continuous indoor deposit but almost no indoor source. Another research conducted in Finland reached a similar conclusion that indoor ozone levels climbed only during a few hours in 1 day (Koponen et al., 2001). Nevertheless, the indoor minimum value was higher than that of outdoor results, which was ascribed to extremely low outdoor level that appeared usually before dawn (Fig. 2(a)). This was caused by intense all-night outdoor $\mathrm{O}_{3}$ consumption, the process of which was weak indoors. I/O ratio (the ratio of indoor concentration to outdoor concentration) of $\mathrm{O}_{3}$ was 0.14 attributed to significant gap between indoor and outdoor concentrations during daytime. Other $\mathrm{O}_{3}$ measurement campaigns found $\mathrm{I} / \mathrm{O}$ ratios ranging from 0.2 to 0.7 (Romieu et al., 1998; Bernard et al., 1999; Weschler, 2001), while the values in this research were less probably owing to tightly sealed building structure and absence of indoor sources.

Table 1. The statistical results of indoor/outdoor $\mathrm{O}_{3}, \mathrm{CO}$ and $\mathrm{PM}_{2.5}$ concentrations and I/O ratios.

\begin{tabular}{llll}
\hline & Ozone $(\mathrm{ppb})$ & Carbon Monoxide $(\mathrm{ppb})$ & $\mathrm{PM}_{2.5}\left(\mu \mathrm{g} \mathrm{m}^{-3}\right)$ \\
\hline Indoor & & & \\
Mean & 4.5 & 447.3 & 23.7 \\
Median & 3.2 & 395.8 & 17.3 \\
SD & 3.9 & 204.9 & 16.8 \\
Range & $0.9-26.6$ & $154.6-1451.2$ & $5.3-133.4$ \\
Outdoor & & & \\
Mean & 32.5 & 450.9 & 56.1 \\
Median & 30.5 & 386.1 & 37.2 \\
SD & 23.5 & 246.9 & 51.2 \\
Range & $0.0-105.7$ & $156.9-2177.2$ & $2.7-242.5$ \\
I/O ratio (median) & 0.14 & 1.01 & 0.46 \\
\hline
\end{tabular}

(a)



(b)



(c)



Fig. 2. The time series of indoor (red lines) and outdoor (blue lines): (a) $\mathrm{O}_{3}$ and (b) $\mathrm{CO}$ concentrations from September 20 to November 3, 2018, and (c) $\mathrm{PM}_{2.5}$ concentrations from October 13 to December 6, 2018. 
For $\mathrm{CO}$, the range of indoor concentrations was from 154.6 to $1451.2 \mathrm{ppb}$ (average: $447.3 \mathrm{ppb}$; median: $395.8 \mathrm{ppb}$ ), and from 156.9 to $2177.2 \mathrm{ppb}$ (average: $450.9 \mathrm{ppb}$; median: $386.1 \mathrm{ppb}$ ) outdoors (Table 1). The outdoor minimum and maximum $\mathrm{CO}$ concentrations were both greater than those indoors, which were in line with the measurement in Shanghai (Zhong et al., 2013). Different from indoor and outdoor $\mathrm{O}_{3}$ concentrations, as shown in Fig. 2(b), the indoor and outdoor $\mathrm{CO}$ concentrations were quite close. It could be because $\mathrm{CO}$ have longer lifetime than $\mathrm{O}_{3}$. The outdoor standard variation was $246.9 \mathrm{ppb}$ compared to $204.9 \mathrm{ppb}$ indoors. Fig. 2(b) indicates that when outdoor $\mathrm{CO}$ concentrations encountered short-term spikes, indoor concentrations responded weakly, which explains higher standard variation of outdoor $\mathrm{CO}$ concentrations. I/O ratio of $\mathrm{CO}$ was close to 1.0 , which resulted from, as mentioned above, quite similar indoor and outdoor concentrations except short-term fluctuations. This value was comparable with other measurements (WHO, 2010; Zhong et al., 2013).

For $\mathrm{PM}_{2.5}$, it shows that indoor $\mathrm{PM}_{2.5}$ mass concentrations varied from 5.3 to $133.4 \mu \mathrm{g} \mathrm{m}^{-3}$ (average: $23.7 \mu \mathrm{g} \mathrm{m}^{-3}$;


was from 2.7 to $242.5 \mu \mathrm{g} \mathrm{m}^{-3}$ (average: $56.1 \mathrm{\mu g} \mathrm{m}^{-3}$; median: $37.2 \mu \mathrm{g} \mathrm{m}^{-3}$ ) (Table 1). Maximum, average and median values of indoor concentrations were significantly lower than values outdoors, which indicates low indooroutdoor air exchange rate and dependence of indoor concentration on transport from outdoor sources. However, the indoor minimum was greater than the outdoor minimum, and this occurred when clean air mass passed outdoors but indoor $\mathrm{PM}_{2.5}$ was not transported outwards timely due to low air exchange rate. The indoor standard variation $\left(16.8 \mu \mathrm{g} \mathrm{m}^{-3}\right)$ was considerably less than the outdoor one $\left(51.2 \mu \mathrm{g} \mathrm{m}^{-3}\right)$, revealing sharper fluctuations of $\mathrm{PM}_{2.5}$ mass concentrations outdoors. The median I/O ratio of $\mathrm{PM}_{2.5}$ was
0.46 in this study. The value was comparable to other measurements ranging from 0.35 to 0.59 (Monn et al., 1995; Landis et al., 2001; Ho et al., 2004; Polidori et al., 2007), but lower than some other measurements (Adgate et al., 2003; Ramachandran et al., 2003; Brunekreef et al., 2005). Therefore, it should be noted that $\mathrm{I} / \mathrm{O}$ ratio of $\mathrm{PM}_{2.5}$ varies widely depending on locations, seasons, ventilation modes and a series of other factors.

\section{Characteristics of Diurnal Cycles}

Diurnal cycles of indoor/outdoor $\mathrm{O}_{3}, \mathrm{CO}$ and $\mathrm{PM}_{2.5}$ concentrations as well as I/O ratios are presented in Fig. 3. The indoor and outdoor $\mathrm{O}_{3}$ concentrations were generally higher from 10:00 LT to 17:00 LT when radiation intensified the formation of outdoor $\mathrm{O}_{3}$ through photochemical reactions. The indoor $\mathrm{O}_{3}$ concentration tracked outdoor concentration well, as other experiments pointed out (Sabersky et al., 1973; Hales et al., 1974), but its variations were much slighter with median values less than $10 \mathrm{ppb}$ all the day. The highest value of indoor $\mathrm{O}_{3}$ appeared at 16:00 LT (7.4 ppb), 1 hour after the zenith of outdoor level. The $\mathrm{I} / \mathrm{O}$ ratio of $\mathrm{O}_{3}$ peaked at 05:00 LT, when the outdoor concentration was low and indoor concentration remained relatively constant during nighttime. Interestingly, when human activities appeared indoors in general (09:00-12:00 LT, 03:00-06:00 LT), indoor concentration continued to increase or maintains high, and even peaked at 16:00 LT, which was inconsistent with some research revealing occupancy of human indoors resulted in reduction of $\mathrm{O}_{3}$ concentrations due to surface reaction with human skin (Rim et al., 2009; Wisthaler and Weschler, 2010; Fischer et al., 2013). It was likely that indoor human appearance, in this study, broke the relatively good airtightness by frequent opening of the door and consequently promoted the transport of outdoor $\mathrm{O}_{3}$ to the room.

The pattern of indoor-outdoor $\mathrm{CO}$ diurnal variations was (a)


(b)


(c)


Fig. 3. Diurnal cycles of indoor concentrations (red lines, bottom panels), outdoor concentrations (blue lines, bottom panels) and $\mathrm{I} / \mathrm{O}$ ratios (black lines with points, top panels) of (a) $\mathrm{O}_{3}$, (b) $\mathrm{CO}$ and (c) $\mathrm{PM}_{2.5}$. Note: shadow areas represent the ranges between $25^{\text {th }}$ and $75^{\text {th }}$ percentiles of indoor and outdoor concentrations. 
considerably different from that of $\mathrm{O}_{3}$, although indoor concentrations also tracked the variations of outdoor concentrations (Fig. 3(b)). The I/O ratio of CO fluctuated around the value of 1.0. The peaks of indoor/outdoor $\mathrm{CO}$ concentrations were found in the morning and late afternoon, which could be caused by incomplete combustion of fuels from vehicles during rush hours (Ye et al., 2000). The indoor concentration peaks were lower than outdoor ones due to the incomplete response of indoor concentrations towards sharp outdoor concentration variations. During the noon, concentrations were slightly lower compared with other periods, which rose from the dilution by boundary layer evolution. The time delay of indoor $\mathrm{CO}$ variations compared to outdoor $\mathrm{CO}$ was observed. Based on the lag correlation calculation, the time lag is about 65 minutes during the campaign. The obvious time lag is regarded as a typical behavior characterizing the response of indoor $\mathrm{CO}$ concentrations to the fluctuations of outdoor $\mathrm{CO}$ when air exchange rate is low (Hayes, 1991; Chaloulakou and Mavroidis, 2002; Chaloulakou et al., 2003). No evidential influence of indoor human activities on indoor $\mathrm{CO}$ concentrations was recorded.

Outdoor concentrations of $\mathrm{PM}_{2.5}$ were higher than indoor concentrations all day long with the I/O ratio fluctuating from 0.38 to 0.67 (Fig. 3(c)). During nighttime, outdoor values were averagely higher, mainly due to lower boundary layer height and accumulation of particles while the indoor concentrations were lower at night. Indoor $\mathrm{PM}_{2.5}$ concentration as well as I/O ratio peaked at 10:00 LT $\left(22.6 \mu \mathrm{g} \mathrm{m}^{-3}\right)$ and 17:00 LT $\left(23.8 \mu \mathrm{g} \mathrm{m}^{-3}\right)$, which corresponded to the schedule of indoor human activity. Considering some behavior, like smoking, was strictly prohibited in the room, the walking of researchers, which triggered re-suspension of particles, was deemed to be the main contributor of the concentration increase. Previous studies have also found the impact of human walking on indoor particle concentrations (Fromme et al., 2007). Additionally, as discussed before, the potential increase of indoor-outdoor air exchange attributed to behavior like opening the door, which changed the "openness" condition of the room, can be another factor that gave rise to indoor concentration increase (Hayes, 1989, 1991).

\section{Indoor-outdoor Correlations}

The correlation between indoor and outdoor $\mathrm{O}_{3}$ concentrations was moderately positive $(r=0.68$; Fig. 4(a)), which was consistent with other measurements (Blondeau et al., 2004; Loupa et al., 2006; Walker and Sherman, 2013). The results also show that when outdoor concentrations were higher than $40 \mathrm{ppb}$, the linear discrete degree turned out to be more scattering. Therefore, it should be taken into consideration that when outdoor level rises to be relatively high, corresponding indoor level can vary relatively widely. In specific cases, to assess indoor concentration based on outdoor concentration and linear function may lead to potential underestimation of indoor concentration. The primary coefficient acquired by linear regression $(0.11)$ was quite close to the $\mathrm{I} / \mathrm{O}$ ratio 0.14 .

The correlation with respect to indoor-outdoor $\mathrm{CO}$ was positive with high correlation coefficient ( $\mathrm{r}=0.82$; Fig. 4(b)). In comparison to the results of $\mathrm{O}_{3}$, the phenomenon of increasingly scattering linear discrete degree was not so marked. Hence, to evaluate indoor $\mathrm{CO}$ concentration using both outdoor concentration and a linear function tends to be accessible and reasonable, at least when CO level is not so high. However, the primary coefficient from linear regression (0.73) was obviously less than the median I/O ratio (1.01).

Fig. 4(c) shows that the correlation between indoor and outdoor $\mathrm{PM}_{2.5}$ mass concentrations was positive with high correlation coefficient $(r=0.82)$. This was consistent with other measurements, e.g., in Guangzhou and Beijing (Huang et al., 2007; Zhao et al., 2015). The primary coefficient resulting from linear regression $(0.27)$ indicated that nearly $27 \%$ of outdoor $\mathrm{PM}_{2.5}$ can infiltrate into indoor environment under the measurement condition. However, the primary coefficient was not comparable with the I/O ratio (0.27 vs. 0.46 for primary coefficient and I/O ratio, respectively).

\section{Impact of Meteorological Factors}

As shown in Fig. 5(a), greater wind speed may enhance the transport into indoor microenvironment, and thus caused larger $\mathrm{I} / \mathrm{O}$ ratio of $\mathrm{O}_{3}$. The slope for indoor $\mathrm{O}_{3}$ concentration above $25 \mathrm{ppb}$ was greater than that for $\mathrm{O}_{3}$ concentration below $10 \mathrm{ppb}$ (0.083 vs. 0.027), indicating that wind speed (a)



(b)



(c)



Fig. 4. The correlations of indoor and outdoor (a) $\mathrm{O}_{3}$, (b) $\mathrm{CO}$ and (c) $\mathrm{PM}_{2.5}$ concentrations with boxes showing $10^{\text {th }}, 25^{\text {th }}$, $50^{\text {th }}, 75^{\text {th }}$ and $90^{\text {th }}$ percentiles in each section. Note: the red lines are the linear fitting results. 
(a)



(b)



(c)



Fig. 5. Scattering plot of (a) wind speed vs. $\mathrm{O}_{3} \mathrm{I} / \mathrm{O}$ ratios (color-coded with indoor $\mathrm{O}_{3}$ concentration; lines represent linear fittings for all data points [black], points with indoor concentration below $10 \mathrm{ppb}$ [red] and points with indoor concentration above $25 \mathrm{ppb}$ [green]), (b) wind speed vs. $\mathrm{PM}_{2.5}$ I/O ratios (color-coded with outdoor relative humidity; the line represents linear fitting for all data points), and (c) daily averaged wind speed vs. daily time lag of CO (color-coded with daily averaged I/O ratios of $\mathrm{CO}$; the line represents linear fitting for all daily data points). Note: the points only with outdoor concentration above $40 \mathrm{ppb}$ and $50 \mathrm{\mu g} \mathrm{m}^{-3}$ were included in Figs. 5(a) and Fig. 5(b), respectively.

played its part more significantly under high-indoorconcentration condition. This can result from human activities that increased indoor-outdoor exchange by altering "openness" condition of the room (e.g., open the door) and consequently caused higher I/O ratio (Hayes, 1991), which also allowed sharper I/O ratio increase when wind speed rose.

Different with $\mathrm{O}_{3}$, Fig. 5(b) indicates that wind speed had little impact on $\mathrm{I} / \mathrm{O}$ ratio of $\mathrm{PM}_{2.5}(\mathrm{r}<0.1)$, but the relationship between outdoor relative humidity and $\mathrm{PM}_{2.5}$ I/O ratio can be seen here. Statistical analysis shows that when outdoor relative humidity ranged from $20 \%$ to $50 \%$, the corresponding median values of outdoor and indoor concentrations and I/O ratio were $60.5 \mu \mathrm{g} \mathrm{m}^{-3}, 24.4 \mu \mathrm{g} \mathrm{m}^{-3}$ and 0.41 , respectively (only the data with outdoor $\mathrm{PM}_{2.5}$ concentration higher than $50 \mu \mathrm{g} \mathrm{m}^{-3}$ was considered in the analysis). As a comparison, when $\mathrm{RH}$ range increased to 50$80 \%$, the median values became $118.1 \mu^{g^{-3}}, 36.5 \mu \mathrm{g} \mathrm{m}^{-3}$ and 0.30 , respectively. Therefore, the aqueous formation of secondary aerosols and hygroscopic growth of PM when RH climbed (Seinfeld et al., 2001; Hu et al., 2010) can increase the outdoor $\mathrm{PM}_{2.5}$ concentration and lead to lower I/O ratio. However, when RH increased to $80-100 \%$, the outdoor $\mathrm{PM}_{2.5}$ concentration decreased while the indoor $\mathrm{PM}_{2.5}$ concentration and $\mathrm{I} / \mathrm{O}$ ratio increased (the median values of outdoor and indoor concentrations and $\mathrm{I} / \mathrm{O}$ ratio were $93 \mu \mathrm{g} \mathrm{m}^{-3}, 41.6 \mu \mathrm{g} \mathrm{m}^{-3}$ and 0.38 , respectively). It is mainly caused by the strong outdoor wet deposition during drizzling rain or fog, which was common in the season of the measurements. Some studies also claimed that high $\mathrm{RH}$ and associated strong hygroscopic growth enhance particle deposition (Hänel, 1982; Quinn and Ondov, 1998; Wolkoff and Kjærgaard, 2007). The negative relationship between PM I/O and outdoor relative humidity is consistent with the findings by Chan (2002).

Fig. 5(c) shows the impact of wind speed on the time lag between indoor and outdoor $\mathrm{CO}$ variations. The daily time lag of $\mathrm{CO}$, which was estimated based on the lag correlation calculation, tended to decrease following the increase of daily averaged outdoor wind speed. It is because high outdoor wind speed enhanced indoor-outdoor exchange and thereby decreased the time lag between indoor and outdoor variations. The existence of time lag can explain the CO I/O ratios exceeding 1.0 (Table 1 and Fig. 5(c)). When outdoor concentration started declining especially after obvious peaks, indoor concentration was rising due to the time lag and caused the indoor concentration higher than the outdoor concentration.

\section{Indoor Air Quality during the $\mathrm{O}_{3}$ and $\mathrm{PM}_{2.5}$ Pollution}

To better understand the indoor air quality, especially the features during $\mathrm{O}_{3}$ and $\mathrm{PM}_{2.5}$ polluted days, typical episodes were selected and analyzed.

An ozone pollution episode was observed from October 2 to October 7, 2018 (Fig. 6). During this episode, continuous high $\mathrm{O}_{3}$ concentrations were observed with highest value reaching about $109 \mathrm{ppb}$ on October 7. The continuous high $\mathrm{O}_{3}$ concentration was caused by appropriate synoptic weather and high anthropogenic emissions during Chinese National Day. Indoor $\mathrm{O}_{3}$ concentration was $10.7 \mathrm{ppb}$ when the outdoor $\mathrm{O}_{3}$ concentration got its maximum on October 7 (109.1 ppb). The highest indoor $\mathrm{O}_{3}$ concentration during the episode was observed on October 6, with the value around $30 \mathrm{ppb}$. On October 7, although the outdoor $\mathrm{O}_{3}$ concentrations was highest at about 14:00 LT, the indoor $\mathrm{O}_{3}$ concentrations peaked at 10:00 LT. Human activities that may increase air exchange (e.g., open the door) (Hayes, 1991; Koponen et al., 2001) can explain such differences according to the working records of the station. Additionally, the indoor $\mathrm{O}_{3}$ concentrations on October 4 and 5 were higher than those on October 2 and 3 although the outdoor $\mathrm{O}_{3}$ concentrations were actually lower. Much higher wind speed was observed on October 4 and 5, supporting that high wind speed promoted the outdoor $\mathrm{O}_{3}$ transport into the room as described above. Indoor and outdoor $\mathrm{CO}$ concentrations during the episode were also presented in Fig. 6. About 60 minutes' time lag of indoor and outdoor $\mathrm{CO}$ concentrations was observed during the episode, which was consistent with the discussion above. 




Fig. 6. Time series of (a) temperature, relative humidity; (b) wind speed, wind direction; (c) indoor/outdoor CO concentrations and (d) indoor/outdoor $\mathrm{O}_{3}$ concentrations from October 2 to October 7, 2018.

From November 27 to December 2, 2018, $\mathrm{PM}_{2.5}$ pollution event with peaks exceeding $200 \mu \mathrm{g} \mathrm{m} \mathrm{m}^{-3}$ was observed at SORPES (Fig. 7). The pollution was mainly caused by local accumulation with obvious near-ground inversion layer and heavy fog. Indoor concentration $\left(42.6 \mu \mathrm{g} \mathrm{m}^{-3}\right)$ during the episode was averagely higher than outdoor level during non-episode days $\left(40.2 \mu \mathrm{g} \mathrm{m}^{-3}\right)$. Indoor $\mathrm{PM}_{2.5}$ concentration can get $65.8 \mu \mathrm{g} \mathrm{m}^{-3}$ when outdoor concentration reached its maximum $\left(242.5 \mu \mathrm{g} \mathrm{m}^{-3}\right)$. Some indoor peaks, such as the one on the afternoon of November 29 with the maximum value of $131.6 \mu \mathrm{g} \mathrm{m}^{-3}$, were recorded. According to the working records of the station, it is likely that it was human activities (e.g., opening the door or walking frequently indoors) that contributed to the peaks indoors by increasing indoor-outdoor air exchange and re-suspension of particles.

The increase of outdoor $\mathrm{PM}_{2.5}$ concentration was significantly more than the rise of concentration indoors during pollution days (e.g., November 29 and November 30). This means when outdoor concentration climbed to certain level, the transport towards indoor microenvironment through infiltration did not increase proportionally as outdoor concentration rose. A feasible explanation is that a penetration limitation existed. It is likely that the increase of transport slowed down when outdoor concentration climbed to certain level, because of limited space of cracks and leaks for infiltration and some other factors. This can also be substantiated by I/O ratios, which was lower during episode than during non-episode days (episode average: 0.40 vs. non-episode average: 0.61 ). Thus, averaged I/O ratio may not be an effective indicator of indoor pollutant accumulation under pollution circumstances, at least for $\mathrm{PM}_{2.5}$.

\section{Estimations of Indoor Pollutant Concentrations}

A statistical method was used for the simulation of indoor
$\mathrm{O}_{3}, \mathrm{CO}$ and $\mathrm{PM}_{2.5}$ concentrations. The method applied in this study is based on a mass-balance equation for pollutants that flow into and out of the indoor microenvironment, including sinks and sources (Shair and Heitner, 1974; Esmen, 1978; Ishizu, 1980). The initial mass-balance equation is from previous study (Hayes, 1991; Chen and Zhao, 2011) and simplified based on the research conditions in this study:

$$
\frac{d c_{i}}{d t}=P F_{a} c_{o}-F_{a} c_{i}-F_{s} c_{i}
$$

where $c_{i}$ and $c_{o}$ are indoor and outdoor concentrations, respectively. $F_{a}$ represents the indoor-outdoor air exchange rate, mainly through infiltration in the case of this study. $F_{S}$ represents the indoor sink rate of pollutants and $P$ represents the penetration factor.

To simplify the equations, $F_{a}, F_{s}$ and $P$ were considered constant and this treatment is common for a given space under the same window/door "openness" condition (Hayes, 1991; Liu and Zhang, 2019). Although the experimental conditions were not strictly unchanged, the simplification is reasonable considering relatively short time of disruption, e.g., human activities. The penetration factor $P$ should be taken into consideration for $\mathrm{PM}_{2.5}$ because only a proportion of particles in the infiltration air succeed in passing through the building shell, while it was set to be one for gases. The rapid surface removal of $\mathrm{O}_{3}$ by indoor materials was significant, so when conducting simulation on indoor $\mathrm{O}_{3}$ concentration, two factors $F_{a}$ and $F_{s}$ were both included. However, $\mathrm{CO}$ had lower reactivity and longer lifetime indoors, so $F_{s}$ was set to be zero when dealing with the prediction of indoor $\mathrm{CO}$ concentration. The equation was solved by iteration with 5 minutes as the length of one step 




Fig. 7. Time series of (a) temperature, relative humidity; (b) wind speed, wind direction and (c) indoor/outdoor $\mathrm{PM}_{2.5}$ concentrations from November 27 to December 2, 2018.

and the data from first 30 days was used. The combination of parameters $\left(F_{a}, F_{s}\right.$ and $\left.P\right)$ that resulted in smallest RMSE between measured and simulated concentrations was calculated for each pollutant.

Based on the CO data, the $F_{a}$ was calculated to be $0.408 \mathrm{~h}^{-1}$. Considering infiltration as the primary pathway, some other research obtained the value of $0.4 \mathrm{~h}^{-1}$ (Persily et al., 2010), 0.02-0.82 $\mathrm{h}^{-1}$ (Shi et al., 2015) and 0.36-1.17 $\mathrm{h}^{-1}$ (Bekö et al., 2016) by modeling or measurement. The value obtained in this study was comparable to them. Considering it is the same indoor environment, it is reasonable to apply this value of $F_{a}$, which represents indoor-outdoor air exchange of the room, to the simulations of $\mathrm{O}_{3}$ and $\mathrm{PM}_{2.5}$. Based on $\mathrm{O}_{3}$ data, the $F_{s}$ of $\mathrm{O}_{3}$ was calculated, which resulted in $2.64 \mathrm{~h}^{-1}$. The $F_{s}$ and $P$ of $\mathrm{PM}_{2.5}$ were also obtained based on $\mathrm{PM}_{2.5}$ data, with value of $0.12 \mathrm{~h}^{-1}$ and 0.60 , respectively. The penetration factor $P(0.60)$ was reasonable in comparison with the results of some other research which obtained the values from measurements in both real buildings and laboratories (Vette et al., 2001; Liu and Nazaroff, 2003; Thatcher et al., 2003).

About 5-day indoor data, which was not applied in obtaining the parameters, was used to verify the estimation (Fig. 8). For simulated indoor $\mathrm{O}_{3}$ concentrations, the simulated result turned out to be fairly congruent during most of the period $(r=0.54$; RMSE $=4.6 \mathrm{ppb})$. It also showed that the method lacked the ability for simulating some short-term fluctuations. Additionally, from the afternoon of October 31 to the afternoon of November 1, 2018, the simulated concentration showed underestimation ( $\mathrm{r}$ and RMSE become 0.75 and $1.6 \mathrm{ppb}$, respectively, if this period is excluded). The incompatibility of this $\sim 1$-day period may merely be brought about by disruption, e.g., the door was not completely closed. A five-fold indoor-outdoor air exchange rate was applied for this period (black dashed line in Fig. 8(a)), which resulted in significantly better agreement between observation and simulation $(r=0.82$; $\mathrm{RMSE}=$ $3.2 \mathrm{ppb}$ ). As for $\mathrm{CO}$, the consistency between measured and simulated concentrations turned out to be markedly good ( $\mathrm{r}$ $=0.96 ;$ RMSE $=29.2 \mathrm{ppb}$ ), although the concentration from simulation was unable to respond to some steep and shortterm oscillations (Fig. 8(b)). Simulation of indoor $\mathrm{PM}_{2.5}$ concentration also got moderate consistency $(r=0.78$; RMSE $=18.1 \mu \mathrm{g} \mathrm{m}^{-3}$ ) (Fig. 8(c)). For some periods (e.g., after December 1), simulated concentration fitted well although short-term fluctuations cannot be embodied. It can be found that from November 28 to December 1, the outdoor $\mathrm{PM}_{2.5}$ peaks frequently exceeded $150 \mu \mathrm{g} \mathrm{m}^{-3}$, and the simulation showed obvious overestimation. This means that high outdoor $\mathrm{PM}_{2.5}$ concentration could cause quite high indoor concentration based on the simulated result, while according to the observation it is limited by penetration as described above. Using lower penetration factor $(P=0.38)$ can improve the simulations (Fig. 8(c)), with correlation coefficient reaching 0.82 and RMSE declining to $9.3 \mu \mathrm{g} \mathrm{m}^{-3}$.

\section{CONCLUSIONS}

This study monitored indoor and outdoor concentrations of $\mathrm{O}_{3}, \mathrm{CO}$ and $\mathrm{PM}_{2.5}$ in real time in suburban Nanjing, located in the Yangtze River Delta, China, from September to December 2018. The indoor measurements were conducted in a room with closed windows and relatively regular daily indoor human activity. The statistical results and diurnal variations were analyzed, and the indoor-outdoor relationships were characterized. A simulation method was used to evaluate parameters for predicting the indoor concentrations. Our findings are summarized as follows:

1) The concentration of $\mathrm{O}_{3}$ was higher outdoors (median: $30.5 \mathrm{ppb}$ ) than indoors (median: $3.2 \mathrm{ppb}$ ); this difference was especially noticeable during the daytime. The indoor concentrations traced the outdoor variations with a moderately positive correlation $(\mathrm{r}=0.68)$ and a median $\mathrm{I} / \mathrm{O}$ ratio of 0.14 . The outdoor (median: $386.1 \mathrm{ppb}$ ) and indoor (median: $395.8 \mathrm{ppb}$ ) concentrations of $\mathrm{CO}$ remained close during most of the period, except during steep short-term oscillations outdoors, and displayed an overall positive correlation of 0.82 and a median $\mathrm{I} / \mathrm{O}$ ratio of 1.01. A delay of approximately 65 minutes in 

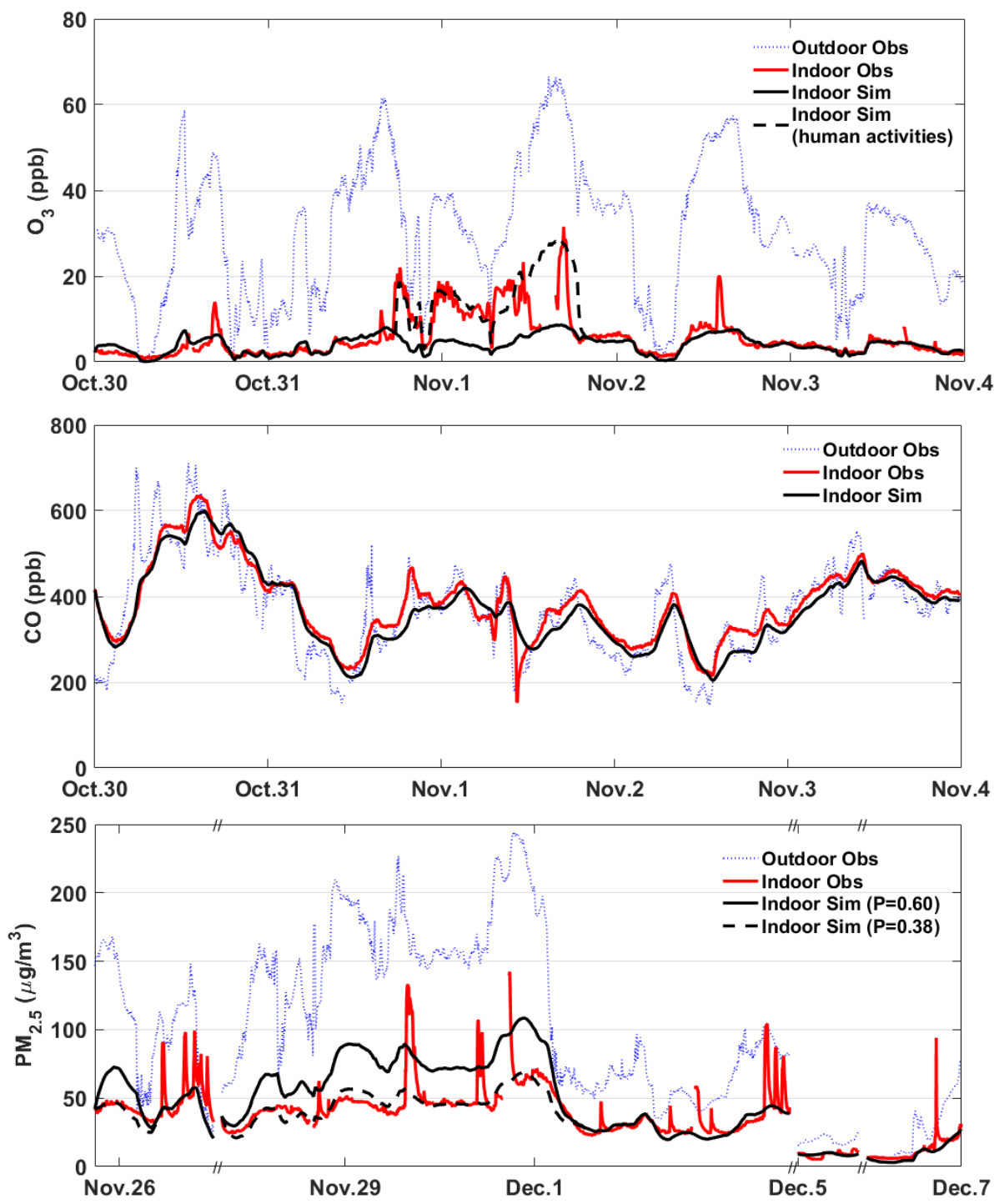

Fig. 8. Comparisons of observed outdoor (blue dashed lines), observed indoor (red solid lines) and simulated indoor (black solid/dashed line) (a) $\mathrm{O}_{3}$, (b) $\mathrm{CO}$ and (c) $\mathrm{PM}_{2.5}$ concentrations during tested periods. Note: the dashed black lines represent the improved simulated indoor concentrations of $\mathrm{O}_{3}$ and $\mathrm{PM}_{2.5}$ considering indoor human activities and limited penetration, respectively.

the indoor variations compared to the outdoor ones was also observed. The outdoor concentration of $\mathrm{PM}_{2.5}$ (median: $37.2 \mu \mathrm{g} \mathrm{m}^{-3}$ ) significantly exceeded the indoor one (median: $17.3 \mu^{-3} \mathrm{~g} \mathrm{~m}^{-3}$ ), and the latter followed the former. The indoor-outdoor correlation was high $(\mathrm{r}=$ 0.82 ), and the median $\mathrm{I} / \mathrm{O}$ ratio was 0.46 . Although human activity indoors greatly influenced the indoor concentrations of $\mathrm{O}_{3}$ and $\mathrm{PM}_{2.5}$ by breaking the airtightness of the room or re-suspending particles, it showed no obvious effect on the indoor $\mathrm{CO}$ concentration.

2) The outdoor wind speed exhibited a positive correlation with the $\mathrm{I} / \mathrm{O}$ ratio for $\mathrm{O}_{3}$, indicating that a higher wind speed may boost transport into indoor microenvironments, but no obvious correlation with the $\mathrm{I} / \mathrm{O}$ ratio for $\mathrm{PM}_{2.5}$ was found. Instead, when the relative humidity $(\mathrm{RH})$ was low, the $\mathrm{PM}_{2.5} \mathrm{I} / \mathrm{O}$ ratio decreased as the RH increased, whereas when the RH was high, this ratio was positively correlated with it. Furthermore, the wind speed was negatively correlated with the time lag for the indoor $\mathrm{CO}$ concentration, suggesting that a higher wind speed increases indoor-outdoor exchange rate and reduces the delay indoors.

3) During the $\mathrm{O}_{3}$ pollution episode of October 2-7, 2018, the indoor concentration was $10.7 \mathrm{ppb}$ at the time when the outdoor concentration reached its maximum of $109.1 \mathrm{ppb}$; the indoor concentration can reach approximately $30 \mathrm{ppb}$ during the episode. During the $\mathrm{PM}_{2.5}$ pollution episode of November 27-December 2, 2018, the average indoor concentration reached $42.6 \mathrm{\mu g} \mathrm{m}^{-3}$, exceeding even the outdoor concentration on unpolluted days $\left(40.2 \mu_{\mathrm{g} \mathrm{m}^{-3}}\right)$. The indoor concentration was $65.8 \mu \mathrm{g} \mathrm{m}^{-3}$ when the outdoor concentration reached its maximum of $242.5 \mathrm{\mu g} \mathrm{m}^{-3}$, and the $\mathrm{I} / \mathrm{O}$ ratio decreased during the episode, reflecting the limitation on penetration. 
4) The indoor-outdoor air exchange rate, indoor sink rate and penetration factor were evaluated using statistical calculation based on a simplified indoor-outdoor massbalance equation. These parameters and the equation were then applied to simulate the indoor concentrations of the pollutants, and a comparison with the measurements confirmed that the predictions fitted the observed data during most of the testing period, especially after considering the indoor human activity and limited particle penetration.

\section{ACKNOWLEDGMENTS}

This work was supported by the National Natural Science Foundation of China (41805101) and Natural Science Foundation of Jiangsu Province (BK20180351). The authors would like to thank the support by National College Student Innovation and Entrepreneurship Training Program.

\section{REFERENCES}

Abt, E., Suh, H.H., Allen, G. and Koutrakis, P. (2000). Characterization of indoor particle sources: A study conducted in the metropolitan Boston area. Environ. Health Perspect. 108: 35-44. https://doi.org/10.1289/ehp. 0010835

Adgate, J., Ramachandran, G., Pratt, G., Waller, L. and Sexton, K. (2003). Longitudinal variability in outdoor, indoor, and personal $\mathrm{PM}_{2.5}$ exposure in healthy nonsmoking adults. Atmos. Environ. 37: 993-1002. https://doi.org/10.1016/S1352-2310(02)00978-0

Astrup, P. (1972). Some physiological and pathological effects of moderate carbon monoxide exposure. $\mathrm{Br} \mathrm{Med}$. J. 4: 447. https://doi.org/10.1136/bmj.4.5838.447

Bekö, G., Gustavsen, S., Frederiksen, M., Bergsøe, N.C., Kolarik, B., Gunnarsen, L., Toftum, J. and Clausen, G. (2016). Diurnal and seasonal variation in air exchange rates and interzonal airflows measured by active and passive tracer gas in homes. Build. Environ. 104: 178187. https://doi.org/10.1016/j.buildenv.2016.05.016

Bell, M.L., Dominici, F. and Samet, J.M. (2005). A metaanalysis of time-series studies of ozone and mortality with comparison to the national morbidity, mortality, and air pollution study. Epidemiology 16: 436-445. https://doi.org/10.1097/01.ede.0000165817.40152.85

Bernard, N.L., Gerber, M.J., Astre, C.M. and Saintot, M.J. (1999). Ozone measurement with passive samplers: Validation and use for ozone pollution assessment in Montpellier, France. Environ. Sci. Technol. 33: 217-222. https://doi.org/10.1021/es971140k

Bi, D., Qiu, Y., Cheng, H., Zhou, Q., Liu, X., Chen, J., Cui, X., Liu, M. and Zhu, Z. (2018). Seasonal characteristics of indoor and outdoor fine particles and their metallic compositions in Nanjing, China. Build. Environ. 137: 118-126. https://doi.org/10.1016/j.buildenv.2018.04.008

Blondeau, P., Iordache, V., Poupard, O., Genin, D. and Allard, F. (2004). Relationship between outdoor and indoor air quality in eight French schools. Indoor Air 15: 2-12. https://doi.org/10.1111/j.1600-0668.2004.00263.x
Brunekreef, B., Janssen, N., Oldenwening, M., Meliefste, K., Hoek, G., Lanki, T., Timonen, K., Vallius, M., Pekkanen, J. and Van Grieken, R. (2005). Personal, indoor, and outdoor exposures to $\mathrm{PM}_{2.5}$ and its components for groups of cardiovascular patients in Amsterdam and Helsinki. Research Report 127. Health Effects Institute, Boston MA, pp. 71-79.

Chaloulakou, A. and Mavroidis, I. (2002). Comparison of indoor and outdoor concentrations of $\mathrm{CO}$ at a public school. Evaluation of an indoor air quality model. Atmos. Environ. 36: 1769-1781. https://doi.org/10.1016/S13522310(02)00151-6

Chaloulakou, A., Mavroidis, I. and Duci, A. (2003). Indoor and outdoor carbon monoxide concentration relationships at different microenvironments in the Athens area. Chemosphere 52: 1007-1019. https://doi.org/10.1016/S0 045-6535(03)00263-7

Chan, A.T. (2002). Indoor-outdoor relationships of particulate matter and nitrogen oxides under different outdoor meteorological conditions. Atmos. Environ. 36: 15431551. https://doi.org/10.1016/S1352-2310(01)00471-X

Chan, C.K. and Yao, X. (2008). Air pollution in mega cities in China. Atmos. Environ. 42: 1-42. https://doi.org/10.10 16/j.atmosenv.2007.09.003

Chen, C. and Zhao, B. (2011). Review of relationship between indoor and outdoor particles: I/O ratio, infiltration factor and penetration factor. Atmos. Environ. 45: 275288. https://doi.org/10.1016/j.atmosenv.2010.09.048

Chen, C., Zhao, B. and Weschler, C.J. (2012). Assessing the influence of indoor exposure to "outdoor ozone" on the relationship between ozone and short-term mortality in US communities. Environ. Health Perspect. 120: 235240. https://doi.org/10.1289/ehp.1103970

Chithra, V. and Nagendra, S.S. (2014). Impact of outdoor meteorology on indoor $\mathrm{PM}_{10}, \mathrm{PM}_{2.5}$ and $\mathrm{PM}_{1}$ concentrations in a naturally ventilated classroom. Urban Clim. 10: 77-91. https://doi.org/10.1016/j.uclim.2014.10. 001

Choo, C.P. and Jalaludin, J. (2015). An overview of indoor air quality and its impact on respiratory health among Malaysian school-aged children. Rev. Environ. Health 30: 9-18. https://doi.org/10.1515/reveh-2014-0065

Cros, C., Morrison, G., Siegel, J. and Corsi, R.L. (2012). Long-term performance of passive materials for removal of ozone from indoor air. Indoor Air 22: 43-53. https://doi.org/10.1111/j.1600-0668.2011.00734.x

Ding, A., Nie, W., Huang, X., Chi, X., Sun, J., Kerminen, V.M., Xu, Z., Guo, W., Petäjä, T. and Yang, X. (2016). Long-term observation of air pollution-weather/climate interactions at the SORPES station: A review and outlook. Front. Environ. Sci. Eng. 10: 15. https://doi.org/ 10.1007/s11783-016-0877-3

Donaldson, K., Brown, D., Clouter, A., Duffin, R., MacNee, W., Renwick, L., Tran, L. and Stone, V. (2002). The pulmonary toxicology of ultrafine particles. J. Aerosol Med. 15: 213-220. https://doi.org/10.1089/08942680232 0282338

Du, Y., Wang, Y., Du, Z., Zhang, Y., Xu, D. and Li, T. (2018). Modeling of residential indoor $\mathrm{PM}_{2.5}$ exposure in 
37 counties in China. Environ. Pollut. 238: 691-697. https://doi.org/10.1016/j.envpol.2018.03.069

Elbayoumi, M., Ramli, N.A., Yusof, N.F.F.M. and $\mathrm{Al}$ Madhoun, W. (2013). Spatial and seasonal variation of particulate matter $\left(\mathrm{PM}_{10}\right.$ and $\left.\mathrm{PM}_{2.5}\right)$ in Middle Eastern classrooms. Atmos. Environ. 80: 389-397. https://doi.org/ 10.1016/j.atmosenv.2013.07.067

Esmen, N.A. (1978). Characterization of contaminant concentrations in enclosed spaces. Environ. Sci. Technol. 12: 337-339. https://doi.org/10.1021/es60139a011

Fadeyi, M.O. (2015). Ozone in indoor environments: Research progress in the past 15 years. Sustain. Cities Soc. 18: 78-94. https://doi.org/10.1016/j.scs.2015.05.011

Fazlzadeh, M., Rostami, R., Hazrati, S. and Rastgu, A. (2015). Concentrations of carbon monoxide in indoor and outdoor air of Ghalyun cafes. Atmos. Pollut. Res. 6: 550555. https://doi.org/10.5094/APR.2015.061

Fischer, A., Ljungström, E. and Langer, S. (2013). Ozone removal by occupants in a classroom. Atmos. Environ. 81: 11-17. https://doi.org/10.1016/j.atmosenv.2013.08.054

Fromme, H., Twardella, D., Dietrich, S., Heitmann, D., Schierl, R., Liebl, B. and Rüden, H. (2007). Particulate matter in the indoor air of classrooms - exploratory results from Munich and surrounding area. Atmos. Environ. 41: 854-866. https://doi.org/10.1016/j.atmosenv.2006.08.053

Gall, E., Darling, E., Siegel, J.A., Morrison, G.C. and Corsi, R.L. (2013). Evaluation of three common green building materials for ozone removal, and primary and secondary emissions of aldehydes. Atmos. Environ. 77: 910-918. https://doi.org/10.1016/j.atmosenv.2013.06.014

Hales, C.H., Rollinson, A.M. and Shair, F.H. (1974). Experimental verification of linear combination model for relating indoor-outdoor pollutant concentrations. Environ. Sci. Technol. 8: 452-453. https://doi.org/10.1021 /es60090a007

Hänel, G. (1982). Influence of relative humidity on aerosol deposition by sedimentation. Atmos. Environ. 16: 27032706. https://doi.org/10.1016/0004-6981(82)90353-5

Hayes, S. (1989). Estimating the effect of being indoors on total personal exposure to outdoor air pollution. JAPCA 39: 1453-1461. https://doi.org/10.1080/08940630.1989.1 0466640

Hayes, S. (1991). Use of an indoor air quality model (IAQM) to estimate indoor ozone levels. J. Air Waste Manage. Assoc. 41: 161-170. https://doi.org/10.1080/10 473289.1991.10466833

Ho, K., Cao, J., Harrison, R.M., Lee, S. and Bau, K. (2004). Indoor/outdoor relationships of organic carbon (OC) and elemental carbon (EC) in $\mathrm{PM}_{2.5}$ in roadside environment of Hong Kong. Atmos. Environ. 38: 6327-6335. https://doi.org/10.1016/j.atmosenv.2004.08.007

Hu, D., Qiao, L., Chen, J., Ye, X., Yang, X., Cheng, T. and Fang, W. (2010). Hygroscopicity of inorganic aerosols: Size and relative humidity effects on the growth factor. Aerosol Air Qual. Res. 10: 255-264. https://doi.org/10.42 09/aaqr.2009.12.0076

Hu, T., Jia, W., Cao, J., Huang, R., Li, H., Liu, S., Ma, T. and Zhu, Y. (2015). Indoor air quality at five site museums of Yangtze River civilization. Atmos. Environ.
123: 449-454. https://doi.org/10.1016/j.atmosenv.2015.1 0.022

Huang, H., Lee, S.C., Cao, J.J., Zou, C.W., Chen, X.G. and Fan, S.J. (2007). Characteristics of indoor/outdoor $\mathrm{PM}_{2.5}$ and elemental components in generic urban, roadside and industrial plant areas of Guangzhou city, China. $J$. Environ. Sci. 19: 35-43. https://doi.org/10.1016/S10010742(07)60006-0

Ishizu, Y. (1980). General equation for the estimation of indoor pollution. Environ. Sci. Technol. 14: 1254-1257. https://doi.org/10.1021/es60170a018

Koponen, I.K., Asmi, A., Keronen, P., Puhto, K. and Kulmala, M. (2001). Indoor air measurement campaign in Helsinki, Finland 1999-the effect of outdoor air pollution on indoor air. Atmos. Environ. 35: 1465-1477. https://doi.org/10.1016/S1352-2310(00)00338-1

Lamble, S., Corsi, R.L. and Morrison, G. (2011). Ozone deposition velocities, reaction probabilities and product yields for green building materials. Atmos. Environ. 45: 6965-6972. https://doi.org/10.1016/j.atmosenv.2011.09. 025

Landis, M.S., Norris, G.A., Williams, R.W. and Weinstein, J.P. (2001). Personal exposures to $\mathrm{PM}_{2.5}$ mass and trace elements in Baltimore, MD, USA. Atmos. Environ. 35: 6511-6524. https://doi.org/10.1016/S1352-2310(01)00407-1

Liu, C., Zhang, Y. and Weschler, C.J. (2014). The impact of mass transfer limitations on size distributions of particle associated SVOCs in outdoor and indoor environments. Sci. Total Environ. 497: 401-411. https://doi.org/10.1016 /j.scitotenv.2014.07.095

Liu, C. and Zhang, Y. (2019). Relations between indoor and outdoor $\mathrm{PM}_{2.5}$ and constituent concentrations. Front. Environ. Sci. Eng. 13: 5. https://doi.org/10.1007/s11783019-1089-4

Liu, D.L. and Nazaroff, W.W. (2003). Particle penetration through building cracks. Aerosol Sci. Technol. 37: 565573. https://doi.org/10.1080/02786820300927

Liu, G., Li, J., Wu, D. and Xu, H. (2015). Chemical composition and source apportionment of the ambient $\mathrm{PM}_{2.5}$ in Hangzhou, China. Particuology 18: 135-143. https://doi.org/10.1016/j.partic.2014.03.011

Liu, J., Dai, X., Li, X., Jia, S., Pei, J., Sun, Y., Lai, D., Shen, X., Sun, H. and Yin, H. (2018). Indoor air quality and occupants' ventilation habits in China: Seasonal measurement and long-term monitoring. Build. Environ. 142: 119-129. https://doi.org/10.1016/j.buildenv.2018.06. 002

Loupa, G., Charpantidou, E., Kioutsioukis, I. and Rapsomanikis, S. (2006). Indoor microclimate, ozone and nitrogen oxides in two medieval churches in Cyprus. Atmos. Environ. 40: 7457-7466. https://doi.org/10.1016 /j.atmosenv.2006.07.015

Lunden, M.M., Revzan, K.L., Fischer, M.L., Thatcher, T.L., Littlejohn, D., Hering, S.V. and Brown, N.J. (2003). The transformation of outdoor ammonium nitrate aerosols in the indoor environment. Atmos. Environ. 37: 5633-5644. https://doi.org/10.1016/j.atmosenv.2003.09.035

Monn, C., Fuchs, A., Kogelschatz, D. and Wanner, H.U. (1995). Comparison of indoor and outdoor concentrations 
of PM-10 and PM-2.5. J. Aerosol Sci. 26: S515-S516. https://doi.org/10.1016/0021-8502(95)97165-B

Nieuwenhuijsen, M.J., Dadvand, P., Grellier, J., Martinez, D. and Vrijheid, M. (2013). Environmental risk factors of pregnancy outcomes: A summary of recent metaanalyses of epidemiological studies. Environ. Health 12: 6. https://doi.org/10.1186/1476-069X-12-6

Passarelli, G.R. (2009). Sick building syndrome: An overview to raise awareness. J. Build. Apprais. 5: 55-66. https://doi.org/10.1057/jba.2009.20

Persily, A., Musser, A. and Emmerich, S.J. (2010). Modeled infiltration rate distributions for US housing. Indoor Air 20: 473-485. https://doi.org/10.1111/j.1600-0668.2010.0 0669.x

Polidori, A., Arhami, M., Sioutas, C., Delfino, R.J. and Allen, R. (2007). Indoor/outdoor relationships, trends, and carbonaceous content of fine particulate matter in retirement homes of the Los Angeles basin. J. Air Waste Manage. Assoc. 57: 366-379. https://doi.org/10.1080/10 473289.2007.10465339

Pope III, C.A., Burnett, R.T., Thun, M.J., Calle, E.E., Krewski, D., Ito, K. and Thurston, G.D. (2002). Lung cancer, cardiopulmonary mortality, and long-term exposure to fine particulate air pollution. JAMA 287: 1132-1141. https://doi.org/10.1001/jama.287.9.1132

Pope III, C.A. and Dockery, D.W. (2006). Health effects of fine particulate air pollution: Lines that connect. J. Air Waste Manage. Assoc. 56: 709-742. https://doi.org/10.1080 /10473289.2006.10464485

Quinn, T. and Ondov, J. (1998). Influence of temporal changes in relative humidity on dry deposition velocities and fluxes of aerosol particles bearing trace elements. Atmos. Environ. 32: 3467-3479. https://doi.org/10.1016/ S1352-2310(98)00047-8

Ramachandran, G., Adgate, J.L., Pratt, G.C. and Sexton, K. (2003). Characterizing indoor and outdoor 15 minute average $\mathrm{PM}_{2.5}$ concentrations in urban neighborhoods. Aerosol Sci. Technol. 37: 33-45. https://doi.org/10.1080/ 02786820300889

Riain, C.N., Mark, D., Davies, M., Harrison, R. and Byrne, M. (2003). Averaging periods for indoor-outdoor ratios of pollution in naturally ventilated non-domestic buildings near a busy road. Atmos. Environ. 37: 41214132. https://doi.org/10.1016/S1352-2310(03)00509-0

Rim, D., Novoselec, A. and Morrison, G. (2009). The influence of chemical interactions at the human surface on breathing zone levels of reactants and products. Indoor Air 19: 324. https://doi.org/10.1111/j.1600-0668. 2009.00595.x

Romieu, I., Lugo, M.C., Colome, S., Garcia, A.M., Avila, M.H., Geyh, A., Velasco, S.R. and Rendon, E.P. (1998). Evaluation of indoor ozone concentration and predictors of indoor-outdoor ratio in Mexico City. J. Air Waste Manage. Assoc. 48: 327-335. https://doi.org/10.1080/10 473289.1998.10463684

Sabersky, R.H., Sinema, D.A. and Shair, F.H. (1973). Concentrations, decay rates, and removal of ozone and their relation to establishing clean indoor air. Environ. Sci. Technol. 7: 347-353. https://doi.org/10.1021/es60076a001
Samet, J.M., Dominici, F., Curriero, F.C., Coursac, I. and Zeger, S.L. (2000). Fine particulate air pollution and mortality in 20 US cities, 1987-1994. N. Engl. J. Med. 343: 1742-1749. https://doi.org/10.1056/NEJM2000121 43432401

Seinfeld, J.H., Erdakos, G.B., Asher, W.E. and Pankow, J.F. (2001). Modeling the formation of secondary organic aerosol (SOA). 2. The predicted effects of relative humidity on aerosol formation in the $\alpha$-pinene-, $\beta$-pinene-, sabinene-, $\delta 3$-carene-, and cyclohexene-ozone systems. Environ. Sci. Technol. 35: 1806-1817. https://doi.org/10. 1021/es001765+

Shair, F.H. and Heitner, K.L. (1974). Theoretical model for relating indoor pollutant concentrations to those outside. Environ. Sci. Technol. 8: 444-451. https://doi.org/10.1021 /es60090a006

Shao, Z., Bi, J., Ma, Z. and Wang, J. (2017). Seasonal trends of indoor fine particulate matter and its determinants in urban residences in Nanjing, China. Build. Environ. 125: 319-325. https://doi.org/10.1016/j.buildenv.2017.09.002

Shi, S., Chen, C. and Zhao, B. (2015). Air infiltration rate distributions of residences in Beijing. Build. Environ. 92: 528-537. https://doi.org/10.1016/j.buildenv.2015.05.027

Sousa, S., Alvim-Ferraz, M. and Martins, F. (2013). Health effects of ozone focusing on childhood asthma: What is now known-A review from an epidemiological point of view. Chemosphere 90: 2051-2058. https://doi.org/10.10 16/j.chemosphere.2012.10.063

Spalt, E.W., Curl, C.L., Allen, R.W., Cohen, M., Adar, S.D., Stukovsky, K.H., Avol, E., Castro-Diehl, C., Nunn, C. and Mancera-Cuevas, K. (2016). Time-location patterns of a diverse population of older adults: The Multi-Ethnic Study of Atherosclerosis and Air Pollution (MESA Air). J. Exposure Sci. Environ. Epidemiol. 26: 349-355.

Stranger, M., Potgieter-Vermaak, S. and Van Grieken, R. (2007). Comparative overview of indoor air quality in Antwerp, Belgium. Environ. Int. 33: 789-797. https://doi.org/10.1016/j.envint.2007.02.014

Tang, C.H., Garshick, E., Grady, S., Coull, B., Schwartz, J. and Koutrakis, P. (2018). Development of a modeling approach to estimate indoor-to-outdoor sulfur ratios and predict indoor $\mathrm{PM}_{2.5}$ and black carbon concentrations for Eastern Massachusetts households. J. Exposure Sci. Environ. Epidemiol. 28: 125-130. https://doi.org/10.1038 /jes.2017.11

Thatcher, T.L., Lunden, M.M., Revzan, K.L., Sextro, R.G. and Brown, N.J. (2003). A concentration rebound method for measuring particle penetration and deposition in the indoor environment. Aerosol Sci. Technol. 37: 847-864. https://doi.org/10.1080/02786820300940

Vette, A.F., Rea, A.W., Lawless, P.A., Rodes, C.E., Evans, G., Highsmith, V.R. and Sheldon, L. (2001). Characterization of indoor-outdoor aerosol concentration relationships during the Fresno PM exposure studies. Aerosol Sci. Technol. 34: 118-126. https://doi.org/10.1080/02786820 117903

Walker, I.S. and Sherman, M.H. (2013). Effect of ventilation strategies on residential ozone levels. Build. Environ. 59: 456-465. https://doi.org/10.1016/j.buildenv.2012.09.013 
Wang, F., Meng, D., Li, X. and Tan, J. (2016). Indooroutdoor relationships of $\mathrm{PM}_{2.5}$ in four residential dwellings in winter in the Yangtze River Delta, China. Environ. Pollut. 215: 280-289. https://doi.org/10.1016/j. envpol.2016.05.023

Weng, M., Zhu, L., Yang, K. and Chen, S. (2010). Levels, sources, and health risks of carbonyls in residential indoor air in Hangzhou, China. Environ. Monit. Assess. 163: 573-581. https://doi.org/10.1007/s10661-009-0859-z

Weschler, C.J. and Shields, H.C. (1997). Potential reactions among indoor pollutants. Atmos. Environ. 31: 34873495. https://doi.org/10.1034/j.1600-0668.2000.010004 269.x

Weschler, C. (2001). Ozone in indoor environments: Concentration and chemistry. Indoor Air 10: 269-288.

Wisthaler, A. and Weschler, C.J. (2010). Reactions of ozone with human skin lipids: Sources of carbonyls, dicarbonyls, and hydroxycarbonyls in indoor air. PNAS 107: 65686575. https://doi.org/10.1073/pnas.0904498106

Wolkoff, P. and Kjærgaard, S.K. (2007). The dichotomy of relative humidity on indoor air quality. Environ. Int. 33: 850-857. https://doi.org/10.1016/j.envint.2007.04.004

Wolkoff, P. (2018). Indoor air humidity, air quality, and health-An overview. Int. J. Hyg. Environ. Health 221: 376-390. https://doi.org/10.1016/j.ijheh.2018.01.015

World Health Organization (WHO) (2010). Who guidelines for indoor air quality: Selected pollutants. World Health Organization. Regional Office for Europe. https://apps.who.int/iris/handle/10665/260127

Ye, S.H., Zhou, W., Song, J., Peng, B.C., Yuan, D., Lu, Y.M. and Qi, P.P. (2000). Toxicity and health effects of vehicle emissions in Shanghai. Atmos. Environ. 34: 419429. https://doi.org/10.1016/S1352-2310(99)00306-4

Zhao, L., Chen, C., Wang, P., Chen, Z., Cao, S., Wang, Q., Xie, G., Wan, Y., Wang, Y. and Lu, B. (2015). Influence of atmospheric fine particulate matter $\left(\mathrm{PM}_{2.5}\right)$ pollution on indoor environment during winter in Beijing. Build. Environ. 87: 283-291. https://doi.org/10.1016/j.buildenv. 2015.02.008

Zhao, Y., Chen, B., Guo, Y., Peng, F. and Zhao, J. (2004). Indoor air environment of residential buildings in Dalian, China. Energy Build. 36: 1235-1239. https://doi.org/10.1 016/j.enbuild.2003.09.011

Zhong, K., Yang, F. and Kang, Y. (2013). Indoor and outdoor relationships of $\mathrm{CO}$ concentrations in natural ventilating rooms in summer, Shanghai. Build. Environ. 62: 69-76. https://doi.org/10.1016/j.buildenv.2013.01.010

Received for review, October 4, 2019

Revised, March 10, 2020

Accepted, March 22, 2020 